\title{
SURGICAL ANALYSIS OF LYMPH NODE POSITIVITY AFTER NEOADJUVANT THERAPY
}

\section{Análise cirúrgica da positividade linfonodal após neoadjuvância quimioterápica Análisis quirúrgico de la positividad de los ganglios linfáticos después de la quimioterapia neoadyuvante}

Rodrigo Ferreira Bernardi* (D), Sergio Bruno Bonatto Hatschbach¹ (D), José Clemente Linhares ${ }^{1}$ (D), Danila Pinheiro Hubie1, Rafaela da Silva² (i)

\section{ABSTRACT}

Introduction: Breast cancer is the most prevalent tumor in women around the world, affecting 1 in 10 women in Brazil. Therefore, providing surgeries that can increase cure rates and provide less comorbidities than those that occur today is a challenge. Until the last decade, performing lymphadenectomy, after neoadjuvant therapy was mandatory. However, new studies could prove that, for some cases, the sentinel lymph node biopsy can be an option. Objective: To analyze the positivity rates of lymphadenectomy, after neoadjuvant therapy. Methods: A total of 152 patients who underwent lymphadenectomy were assessed, from 2012 to 2014; they were separated into two groups of arms: those that had clinically positive armpit results before chemotherapy in one arm, and those that had negative armpit results before chemotherapy. Results: Out of 152 patients, 57 had negative armpit results before chemotherapy, $71 \%$ continued to have negative results following lymphadenectomy. In the group containing 95 patients with positive armpit results (following neoadjuvant therapy), $43.6 \%$ of them were free from neoplasms after undergoing lymphadenectomy. Discussion: The results of this study were similar to those found in worldwide literature for lymph node rates in all groups. It means that both the staging before chemotherapy and neoadjuvant therapy are performed with the same efficacy rates as in other studied hospitals. Moreover, there is evidence on the authorization to perform sentinel lymph node biopsy after chemotherapy in those patients who had clinically negative armpit results prior to neoadjuvant therapy. Conclusion: Sentinel lymph node biopsy is a safe and efficient technique to be used in patients who underwent chemotherapy and had negative armpit results. Whenever needed, such technique should always be encouraged.

KEYWORDS: breast cancer; sentinel lymph nodes; diagnosis.

\section{RESUMO}

Introdução: O câncer de mama é a neoplasia que mais acomete mulheres no mundo, sendo uma a cada 10 mulheres que irão ser acometidas, no Brasil. Portanto, proporcionar cirurgias que tenham menor morbidade com as mesmas ou maiores taxas de cura é um desafio. De acordo com o exposto, até a década passada realizar linfadenectomia após quimioterapia neoadjuvante era mandatório, porém novos estudos estão conseguindo provar que para alguns casos a biópsia de linfonodo sentinela pode ser uma opção. Objetivo: Este estudo analisou o índice de positividade de linfadenectomias pós-quimioterapia neoadjuvante. Métodos: Foram avaliadas 152 pacientes, entre 2012 e 2014, que realizaram cirurgia de linfadenectomia, separado-as em dois braços, aquelas que eram axilas positivas clinicamente antes da quimioterapia em um braço, e no outro, axilas negativas antes do tratamento quimioterápico. Resultados: Desmembrando os 152 pacientes, 57 desses com axilas negativas anteriores à quimioterapia, obtivemos que 71\% permaneceram negativas após linfadenectomia. No grupo de 95 pacientes com axilas positivas, após neoadjuvância quimioterápica, 43,6\% resultaram estarem livres de comprometimento neoplásico após linfadenectomia . Discussão: Os resultados denotados no índice de positividade de linfonodos em todos os grupos foram muito semelhantes à literatura mundial, demonstrando que nosso estadiamento antes da quimioterapia e nosso tratamento neoadjuvante são realizados com a mesma eficácia do que de outros hospitais já estudados. Também pudemos denotar que estamos autorizados a realizar biópsia de linfonodo sentinela pós-quimioterapia naquelas pacientes as quais eram negativas as axilas clinicamente, antes do tratamento neoadjuvante. Conclusão: A biópsia de linfonodo sentinela é uma técnica segura e eficaz em pacientes pós-quimioterapia com axilas negativas e devemos sempre incentivar essa técnica, quando for indicado.

PALAVRAS-CHAVE: câncer de mama; linfonodo sentinela; diagnóstico.

${ }^{1}$ Hospital Erasto Gaertner - Curitiba (PR), Brazil.

${ }^{2}$ Hospital e Maternidade Santa Brígida - Curitiba (PR), Brazil

*Corresponding author: drrodrigobernardi@hotmail.com

Conflict of interest: nothing to declare.

Received on: 02/12/2019. Accepted on: 02/24/2019 


\section{INTRODUCTION}

Apart from non-melanoma skin cancer, breast cancer is the most prevalent in the female population all over the world. It responded for $25 \%$ of all types of cancer in 2012, that is, roughly 1.7 million cases ${ }^{1}$.

In Brazil, when not considering non-melanoma skin cancers, breast cancer is also the most prevalent among women from all regions, except from the North region, where cervical cancer ranks first. In 2016, 57,960 new cases were estimated, which represents an incidence rate of 56.2 cases per 100 thousand women².

Between 1894 and 1907, Halsted described his radical mastectomy technique, which included removing the breasts and chest muscles through axillary lymph node dissection/lymphanedectomy, with a $31 \%$ rate of patients free from the disease within five years ${ }^{3}$.

In the early 1970s, Kett et al. reported that the first regional lymph node could be identified in breast cancer. Thereafter, primary tumor was found to be drained by afferent lymph vessels, that travel to the first sentinel lymph node, and in case metastasis occurs, it will affect primarily that lymph node ${ }^{4}$.

Until 1990, axillary lymphadenectomy was mandatory, but Giuliano et al. demonstrated, with selective lymphadenectomy, which is the sentinel lymph node with vital isosulfan blue staining, a technique with less morbidity rates and more safety to define axillary staging ${ }^{5}$.

In 2003, Veronesi et al. established that sentinel lymph node biopsy (SNB) was a safe and accurate technique for identifying axillary metastasis in women with small breast tumors ${ }^{6}$.

Since 1970, neoadjuvant chemotherapy has been employed to treat locally advanced tumors. It has high response rates and allows surgery for initially unresectable tumors and breast-conserving surgery ${ }^{5}$.

Tumor resection with total axillary lymphadenectomy is a practice in most hospitals worldwide, after neoadjuvant chemotherapy. In 2009, however, Van Deurzen et al. conducted a systematic review, including 27 studies, with a total of 2,148 patients undergoing neoadjuvant chemotherapy, and showed that the detection rate of the sentinel lymph node was $90.9 \%$ and that of false negative, $10.5 \%$. Despite that, data were still insufficient to indicate sentinel lymph node as a standard procedure after neoadjuvant chemotherapy ${ }^{7}$.

After several studies, such as Sentina and the National Surgical Adjuvant Breast and Bowel Project Protocol B-27 (NSABP-27), the practice of sentinel lymph node became a possibility ${ }^{7}$. In 2015, Mautner et al. performed a review and analyzed that sentinel lymph node after neoadjuvant chemotherapy is acceptable, provided that two tracers are used to identify sentinel lymph nodes and at least three lymph nodes are found ${ }^{8,9}$.

The treatment protocol of the Gynecology and Breast Service of Hospital Erasto Gaertner recommends neoadjuvant chemotherapy for patients with:

- Clinically positive axillary lymph node at diagnosis;
- Tumors greater than $25 \%$ of breast size, even with negative lymph node.

After the end of neoadjuvant therapy (around six months), these patients are taken to surgery for local tumor treatment (radical mastectomy or conservative surgery followed by radiotherapy), and regionally, undergoing axillary lymphadenectomy, including if they present total clinical response, axillary lymph nodes or even those that were previously clinically negative armpits.

However, imaging studies are proving that the clinical and pathological correlation of axillary lymph node positivity and the postoperative histological results have been confirmed. In this context, with the concept of sentinel lymph nodes, it has been possible to better stratify patients who are candidates for axillary lymphadenectomy.

The concept of sentinel lymph node advocates the injection of contrast with periareolar radiolabel on the eve of surgery, followed by the investigation of the first lymph node of the intraoperative drainage pathway, with detection aided by a Gamma Probe. After the sentinel lymph node is identified and resected, it is sent for a histopathological examination through intraoperative frozen section procedure. If positive, complete axillary lymphadenectomy is indicated. In case it results negative, the surgery is terminated. Studies support the safety of not performing axillary lymphadenectomy in case of negative sentinel nodes, due to the low incidence of metastases.

Axillary lymphadenectomy is a procedure of relative morbidity and low impact on the patients' quality of life. Of all cases, $20 \%$ evolve with operated limb lymphedema, movement restriction and the possibility of serious complications such as thrombosis, or even amputation. In this sense, it must be indicated for carefully selected cases, without any harm to cancer treatment.

\section{OBJECTIVE}

To analyze the positivity rates of post-lymphadenectomy and post-neoadjuvant axillary lymph nodes and the possibility of sentinel lymph node biopsy.

\section{METHODS}

An analytical, descriptive and retrospective hospital-based study was performed. The eligible population consisted of women with breast cancer (ICD 10 C50 - malignant breast cancer), whose data were obtained from the Hospital Cancer Records of Hospital Erasto Gaertner, through the system based on medical record review (physical and electronic Tasy System), which covers all patients operated between 2012 and 2014, eligible for the survey. 
The inclusion criterion for research was to be a patient who underwent neoadjuvant chemotherapy, after a medical examination and designation for this therapy. Patients who failed to complete at least half of the initially proposed chemotherapy cycle were excluded.

All patients, after treatment, underwent lymphadenectomy associated with breast resection, either total or partial. A total of 162 cases were selected, and 152 patients were eligible for the study at the end of the evaluation. These 152 women were grouped into two large categories: a group with those who, in the clinical examination performed by the mastology team (resident and preceptor) and by the clinical oncology team (resident and preceptor) at initial care, had clinically negative armpit results; and the other group with those with clinically positive armpit results. In both groups, all patients underwent neoadjuvant chemotherapy and breast resection surgery with axillary lymphadenectomy. The outcome of the pathological anatomy of the axillary lymph node specimen was evaluated according to:

- $\quad$ unaffected lymph nodes: pN0;

- $\quad$ from 1 to 3 affected lymph nodes: $\mathrm{pN1}$;

- from 4 to 9 affected lymph nodes: pN2;

- 10 or more affected lymph nodes: pN3;

The tumor, node, metastasis (TNM) system was another factor used to designate arms in the groups; $\mathrm{T}$ represents the tumor size (T1, T2, T3, and T4).

For data collection, a questionnaire containing the most important information was the medical record number, clinically assessed primary tumor, clinically regional lymph node, clinically distant metastasis, pathological primary tumor, pathological regional lymph node, pathological distant metastasis, histological type, immunohistochemical profile, surgery performed, and drugs used in chemotherapy. The collected data were tabulated and evaluated using the OpenEpi program, which allows data analysis based on descriptive statistics.

\section{RESULTS}

The study population consisted of 152 patients with breast cancer. Of these, 57 (37.5\%) were grouped into a first category of patients with clinically negative armpit results.

A distinction considering arms was made as to TNM, as follows: T2N0 25 (43.8\%) women, T3N0 28 (49.1\%), and T4N0 4 (7.01\%).

Of the $25 \mathrm{~T} 2 \mathrm{~N} 0$ patients, after lymphadenectomy, the rates were as follows: 17 (68\%) ypN0; 6 (24\%) ypN1; and 2 (8\%) ypN2. Of the $28 \mathrm{~T} 3 \mathrm{~N} 0$ cases (women who underwent lymphadenectomy), 20 (71.4\%) were ypN0; 6 (21.4\%) ypN1; 1 (3.5\%) ypN2; and 1 (3.5\%) ypN3. In the last arm, there were 4 (7.01\%) T4N0 women, all ypN0 (see Table 1). When all these 57 patients were allocated only according to the lymph nodes studied in the pathological anatomy, 41 (71.9\%) were ypN0; 12 (21.05\%) ypN1; 3 (5.26\%) ypN2; and $1(1.75 \%)$ ypN3, according to Graphic 1.

Regarding the 95 (62.5\%) patients from the other group (those with clinically positive armpit results), 2 (2.1\%) T1N1 were evaluated after lymphadenectomy, of which 1 (50\%) ypN0, and 1 (50\%) ypN1. Of the 36 (37.89\%) T2N1 cases, that underwent lymphadenectomy, 13 (36.11\%) were ypN0; 18 (50\%) ypN1; 4 (11.11\%) ypN2; and $1(2.77 \%)$ ypN3. Only 1 (10.52\%) patient was clinically diagnosed

Table 1. Groups and their percentages as to the number of negative armpit results, according to the physical examination.

\begin{tabular}{|c|c|c|}
\hline \multirow{8}{*}{$\begin{array}{l}\text { Negative } \\
\text { armpit }\end{array}$} & \multirow{3}{*}{ T2N0: 43\% (25) } & ypNo: 68\% (17) \\
\hline & & ypN1: 24\% (6) \\
\hline & & ypN2: 8\% (2) \\
\hline & \multirow{4}{*}{ T3N0: 49.1\% (28) } & ypN0: $71.4 \%$ (20) \\
\hline & & ypN1: 21.4\% (6) \\
\hline & & ypN2: 3.5\% (1) \\
\hline & & ypN3: 3.5\% (1) \\
\hline & T4N0: $7.01 \%(4)$ & ypN0:100\% (4) \\
\hline
\end{tabular}

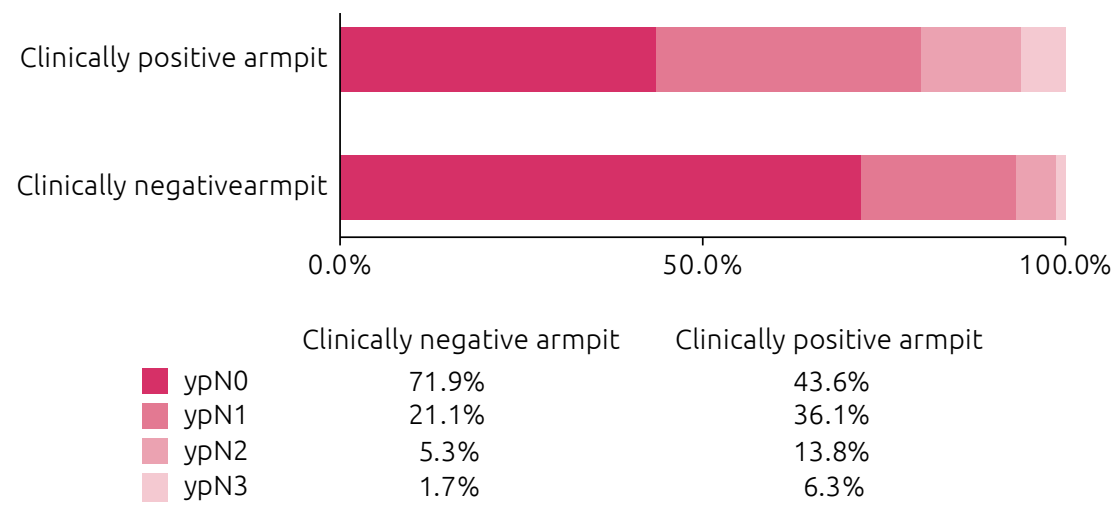

Graph 1. Proportion of negative and positive armpits. 
T2N2, and the pathological lymph node status observed was ypN1. As to T3N1, 25 cases (26.31\%) were reported. Of these, 15 (60\%) ypN0; 5 (20\%) ypN1; 3 (12\%) ypN2; and 2 (8\%) ypN3. Of the 7 T3N2 (7.36\%) women, 2 (28.57\%) were ypN0; 4 (57.14\%) ypN1; and 1 (14.28\%) ypN2. Besides that, 18 T4N1 (18.94\%) case were observed, of which 10 (55.55\%) were ypN0; 4 (22.22\%) ypN1; 2 (11.11\%) ypN2; and $2(11.11 \%)$ ypN3. Finally, $6(5.26 \%)$ cases were T4N2, with 1 (16.6\%) pN1; 4 (66\%) pN2; and 1 (16.6\%) pN3, according to Table 2. When the total of 95 patients was allocated only according to the lymph nodes studied in the pathological anatomy, 41 cases (43.6\%) were ypN0; 34 (36.1\%) ypN1; 14 (14.1\%) ypN2; and 6 (6.3\%) ypN3.

\section{DISCUSSION}

Over the last two decades, scientific publications have been more concerned with the morbidity caused by breast cancer treatment, without reducing the effectiveness of the treatment ${ }^{8}$. Studies have also investigated the percentage of positive armpits results following neoadjuvant chemotherapy and the possibility of SNB in these cases.

In the 1990s, the NSABP B-18 study had already shown that lymph node positivity was of $40 \%$ post-chemotherapy and lower compared to patients who underwent surgery first, i.e., $58 \%$.

Table 2. Groups and their percentages as to the number of positive armpit results, according to the physical examination.

\begin{tabular}{|c|c|c|}
\hline \multirow{21}{*}{$\begin{array}{l}\text { Positive } \\
\text { armpit }\end{array}$} & \multirow{2}{*}{ T1N1: 2.1\% (2) } & ypN0: $50 \%$ (1) \\
\hline & & ypN1: 50\% (1) \\
\hline & \multirow{4}{*}{ T2N1: 37.8\% (36) } & ypNo: 36.1\% (13) \\
\hline & & ypN1: 50\% (18) \\
\hline & & ypN2: 11.1\% (4) \\
\hline & & ypN3: $2.7 \%$ (1) \\
\hline & T2N2: $1.05 \%$ (1) & ypN1:100\% \\
\hline & \multirow{4}{*}{ T3N1: 26.3\% (25) } & ypNo: 60\% (15) \\
\hline & & ypN1: 20\% (5) \\
\hline & & ypN2:12\% (3) \\
\hline & & ypN3: 8\% (2) \\
\hline & \multirow{3}{*}{ T3N2: $7.3 \%(7)$} & ypN0: $28.5 \%$ (2) \\
\hline & & ypN1: $57.1 \%$ (4) \\
\hline & & ypN2:14.2\% (1) \\
\hline & \multirow{4}{*}{ T4N1: 18.9\% (18) } & ypN0: $55.5 \%$ (10) \\
\hline & & ypN1:22.2\% (4) \\
\hline & & ypN2: 11.1\% (2) \\
\hline & & ypN3: 11.1\% (2) \\
\hline & \multirow{3}{*}{ T4N2: $6.3 \%(6)$} & ypN1: $16.6 \%$ (1) \\
\hline & & ypN2: 66\% (4) \\
\hline & & ypN3: 16.6\% (1) \\
\hline
\end{tabular}

The largest single-hospital experience occurred at MD Anderson Cancer Center by Hunt et al., between 1997 and 2007, in which 575 patients with negative sentinel lymph node by aspiration biopsy first underwent chemotherapy, and then underwent axillary lymphadenectomy. In $97.4 \%$ of these patients, sentinel lymph node was identified, with a false negative rate of 5.9\%. The authors demonstrated that a false negative event was more likely when fewer than two lymph nodes were removed. In these patients, in case of T2, lymph node positivity was $20.5 \%$, and for T3, $30.4 \%^{10}$.

After that, most studies focused on observing the postchemotherapy lymph node identification rate, as in the article by Classe et al., from 2009. In this study, sentinel lymph node biopsy was identified for patient $\mathrm{N} 1$ at $81.5 \%$. and, for N0, $94 \%$, with a false negative rate of $15 \%$ as opposed to $9.4 \%$ for each case, respectively ${ }^{11}$.

In two meta-analyses by Xing et al. and Kelly et al., who evaluated SNB after chemotherapy in 3,072 patients, sentinel lymph node biopsy was found reliable after neoadjuvant chemotherapy ${ }^{12,13}$.

In 2010, when clinically assessing the reliability of lymph node evaluation, Chung et al. reported that the positive predictive value (PPV) of axillary ultrasound (US) compared to physical examination was 93 vs. 83\%, respectively. The negative predictive value (NPV) of US was $58 \%$, compared to $52 \%$ of the physical examination. These findings agree with those from parallel studies. An algorithm was recommended: if the patient has clinically negative armpit results, she will perform the axillary US, by needle aspiration, if any suspicious nodules are detected. If axillary US does not identify any suspected axillary lymph nodes, the SNB should be performed before chemotherapy is initiated, or after the neoadjuvant treatment ${ }^{14}$.

Of the 152 patients, 57 with clinically negative armpit results were examined. In T3N0 patients, the positivity in lymphadenectomy was $28.6 \%$, slightly lower than in other studies; T2N0 had $32 \%$ of positivity, higher than that found in other articles. Interestingly, all T4N0 patients presented negative armpit results. When only lymph nodes were evaluated, there is a $28.1 \%$ of positivity of armpit results, which is consistent with other statistics, such as that by Hunt et al. ${ }^{10}$. Such data confirms that the neoadjuvant treatment at Hospital Erasto Gaertner brings similar results to those presented in other articles, regarding axillary lymph nodes.

In the 95 patients who had positive armpit results in the clinical examination prior to chemotherapy, a still high lymph node positivity rate of $54(56.4 \%)$ patients after axillary lymphadenectomy was detected. However, in 41 cases (43.6\%), lymphadenectomy was negative for lymph nodes, suggesting that chemotherapy could have spared these patients from unnecessary lymphadenectomies. On the other hand, as stated by Van Deurzen et al., in patients with positive armpit results, chemotherapy acts on metastatic lymph nodes causing fibrosis, which may alter the local lymphatic drainage pattern?. 
Another aspect to be considered are the low detection rates of the sentinel lymph node, which are $80.1 \%$ after chemotherapy, reported by Classe et al., in 2009, and Kuehn et al. in the 2013 Sentina study, values described by these authors as unacceptable ${ }^{8,11}$.

In short, in the book Diseases of the breast by Harris et al., sufficient data are said to be already available to demonstrate that sentinel lymph node surgery following neoadjuvant systemic treatment is an appropriate treatment for patients with clinically negative lymph node results. As for patients with positive lymph nodes, there are not enough studies for systematic performances. Surgery can be performed individually in each case ${ }^{15}$.

\section{CONCLUSION}

In several articles and a base textbook of Mastology and Oncology, the SNB, following neoadjuvant chemotherapy in clinically negative armpit results can and should be performed. As to patients with positive lymph nodes, literature does not have enough data for not practicing lymphadenectomy. We observed that clinical analysis before chemotherapy and neoadjuvant treatment at Hospital Erasto Gaertner provide similar rates compared to those from literature worldwide on lymph node positivity. The algorithm proposed by Chung et al. ${ }^{14}$, previously described in the study, could be used at Erasto Gaertner Hospital, without causing major additional costs and significantly improving morbidity rates, thanks to the axillary lymphadenectomy surgery.

\section{REFERENCES}

1. World Health Organization. International Agency for Research on Cancer. Globocan. Genebra: World Health Organization; 2012.

2. Instituto Nacional de Câncer JoséAlencar Gomes daSilva. Estimativa 2016. Incidência do Câncer no Brasil. Rio de Janeiro: INCA; 2015.

3. Halsted WS. The results of radical operations for the cure of carcinoma of de breast. Ann Surg. 1907;46(1):1-19. https://doi. org/10.1097/00000658-190707000-00001

4. Kett K, Varga G, Lukacs L. Direct lymphography of the breast. Lymphology. 1970;3(1):2-12.

5. Giuliano AE, Kirgan DM, Guenther JM, Morton DL. Lymphatic mapping and sentinel lymphadenectomy for breast cancer. Ann Surg. 1994;220(3):391-401Veronesi U, Paganelli G, Viale G, Luini A, Zurrida S, Galimberti V, et al. A randomized comparison of sentinelnode biopsy with routine axillary dissection in breast cancer. NEngl J Med. 2003;349(6):546-53. https://doi.org/10.1056/NEJMoa012782

6. Van Deurzen CHM, Vriens BE, Tjan-Heijnen VC, van der Wall E, Albregts M, van Hilligersberg R, et al. Accuracy of sentinel node biopsy after neoadjuvant chemotherapy in breast cancer patients: A systematic review. Eur J Cancer. 2009;45(18):312430. https://doi.org/10.1016/j.ejca.2009.08.001

7. Kuehn T, Bauerfeind I, Fehm T, Fleige B, Hausschild M, Helms $\mathrm{G}$, et al. Sentinel-lymph-node biopsy in patients with breast cancer before and after neoadjuvant chemotherapy (SENTINA): A prospective, multicentre cohort study. Lancet Oncol. 2013;14(7):609-18.

8. Mautner SK, Cody HS 3rd. Sentinel node biopsy after neoadjuvant chemotherapy for node-positive breast cancer: Does axillary ultrasound improve performance?
J Clin Oncol. 2015;33(30):3375-8. https://doi.org/10.1200/ JCO.2014.60.3316

9. Hunt KK, Yi M, Mittendorf EA, Guerrero C, Babiera GV, Bedrosian I, et al. Sentinel lymph node surgery after neoadjuvante chemotherapy is accurate and reduces the need for axillary dissection in breast cancer patients. Ann Surg. 2009;250(4):558-66. https://doi.org/10.1097/ SLA.0b013e3181b8fd5e

10. Classe JM, Bordes V, Campion L, Mignotte H, Dravet F, Leveque J, et al. Sentinel lymph node biopsy after neoadjuvant chemotherapy for advanced breast cancer: results of ganglion sentinelle et chemiotherapie neoadjuvant, a French prospective multicentric study. J Clin Oncol. 2009;27(5):726-32. https://doi.org/10.1200/ JCO.2008.18.3228

11. Xing Y, Foy M, Cox DD, Kuerer HM, Hunt KK, Cormier JN. Meta-analysis of sentinel lymph node biopsy after preoperative chemotherapy in patients with breast cancer. By J Surg. 2006;93(5):539-46. https://doi.org/10.1002/bjs.5209

12. Kelly Am, Dwamena B, Cronin P, Carlos RC. Breast cancer sentinel node identification and classification after neoadjuvant chemotherapy-systematic review and meta analysis. Acad Radiol. 2009;16(5):551-63. https://doi.org/10.1016/j.acra.2009.01.026

13. Chung A, Giuliano A. Axillary Staging in the Neoadjuvant Setting. Ann Surg Oncol. 2010;17(9):2401-10. https://doi. org/10.1245/s10434-010-1001-8

14. Harris JR, Lippman ME, Morrow M, Kent Osborne C. Diseases of the breast. $5^{\mathrm{a}}$ ed. Wolters Kluwer; 2014. 1224 p. 